\title{
Article \\ Gender Differences in Physical Fitness Characteristics in Professional Padel Players
}

\author{
Francisco Pradas ${ }^{1}\left(\mathbb{D}\right.$, Alejandro Sánchez-Pay ${ }^{2, *} \mathbb{D}$, Diego Muñoz ${ }^{3} \mathbb{D}$ and Bernardino J. Sánchez-Alcaraz ${ }^{4} \mathbb{D}$ \\ 1 ENFYRED Research Group, Faculty of Health Sciences and Sport, University of Zaragoza, \\ 50009 Huesca, Spain; franprad@unizar.es \\ 2 Human Performance and Sports Science Laboratory, Faculty of Sport Sciences, University of Murcia, \\ 30720 San Javier, Spain \\ 3 Department of Musical, Plastic and Corporal Expression, Faculty of Sport Sciences, \\ University of Extremadura, 06006 Badajoz, Spain; diegomun@unex.es \\ 4 Department of Physical Activity and Sport, Faculty of Sport Sciences, University of Murcia, \\ 30720 San Javier, Spain; bjavier.sanchez@um.es \\ * Correspondence: aspay@um.es
}

Citation: Pradas, F.; Sánchez-Pay, A.; Muñoz, D.; Sánchez-Alcaraz, B.J. Gender Differences in Physical Fitness Characteristics in Professional Padel Players. Int. J. Environ. Res. Public Health 2021, 18, 5967. https:// doi.org/10.3390/ijerph18115967

Academic Editors: Jon

Øyvind Odland,

Jaime Fernandez-Fernandez,

Urs Granacher and

Manuel Moya-Ramon

Received: 9 April 2021

Accepted: 27 May 2021

Published: 2 June 2021

Publisher's Note: MDPI stays neutra with regard to jurisdictional claims in published maps and institutional affiliations.

Copyright: (c) 2021 by the authors. Licensee MDPI, Basel, Switzerland. This article is an open access article distributed under the terms and conditions of the Creative Commons Attribution (CC BY) license (https:// creativecommons.org/licenses/by/ $4.0 /)$

\begin{abstract}
The aims of the present study were to examine the fitness characteristics of professional padel players and to determine differences in physical performance regarding players' gender. Thirty professional padel players (men: $n=15$, age $=27.4 \pm 6.8$ years, height $=177.9 \pm 4.0 \mathrm{~cm}$; women: $n=15$, age $=30.0 \pm 4.2$ years, height $=166.6 \pm 4.8 \mathrm{~cm}$ ) completed a 4-day evaluation process, including: isometric handgrip strength, sit and reach, $10 \times 5$ shuttle test, countermovement jump (CMJ), squat jump (SJ), Abalakov test, one-repetition maximum test (bench press, leg extension, leg curl, lat pulldowns, overhead press, and shoulder press), anthropometry and $\mathrm{VO}_{2}$ max tests. The men players had higher values in terms of weight, height, one maximum repetition, jump tests (CMJ and $\mathrm{ABK})$ and $\mathrm{VO}_{2}$ max test than the women $(p<0.005)$. By contrast, the women had higher values for fat mass ( $p=0.005$; ES: 2.49). The values from this multifaceted test battery can be a useful guide for coaches regarding players' development in future evaluations and monitoring.
\end{abstract}

Keywords: physical fitness; racket sport; exercise evaluation; padel

\section{Introduction}

Padel is a racket sport played in pairs, which uses tennis rules and the tennis scoring system, and takes place in a rectangular area $(10 \times 20 \mathrm{~m})$ divided into two halves by a central net, and enclosed in a synthetic glass and metal court, which allows for the use of side and back walls [1]. In recent years, a great increase in the number of participants of different genders and ages has been observed [2]. In addition, this growth has also been reflected in a greater professionalisation and an increase in scientific research [3]. Research has been focused on three fundamental aspects: temporal structure [4-6], players' movements and distance covered on the court $[7,8]$ and game actions, such as technical or tactical parameters $[3,9,10]$.

Padel can be defined as an intermittent sport, which combines short periods of high intensity and frequent actions (0.7-1.5 per second), with alternating rest periods, as established by the game rules (20 s) [4,11]. The phosphagen system (ATP-Pc) is the main path used to obtain energy during the high-intensity actions demanded [7]. On the other hand, the maximal values of lactate obtained during the game were near to $2.4 \mathrm{mmol} / \mathrm{L}$, indicating that anaerobic glycolysis could be less determinant [12]. Finally, the aerobic system could be relevant because of the long duration and mean intensity of the matches, requiring the complex interaction of several physical components (i.e., acceleration, changes in direction, jumps, strength), and metabolic pathways (anaerobic and aerobic) [13]. The strength and conditioning profile in padel includes short-distance sprints and changes 
in direction, upper-body strength and power, intermittent recovery endurance and body balance evaluations $[13,14]$. Due to the importance of muscular power in the game of padel, strength and power testing has become an important monitoring and evaluation tool to optimise the neuromuscular performance factors related to the major strokes [15]. The padel physical demands and workload reported, using heart rate, speed of movement and distance covered, appear to be beneficial for health promoting purposes; nevertheless, intensity patterns and fitness characteristics may change according to players' performance levels [16].

Despite its usefulness, there is an alarming lack of investigations examining physical fitness testing in padel [13]. This information allows coaches to assess the strengths and weaknesses of players and to identify the most relevant factors in game performance $[17,18]$. Regarding the fitness and anthropometric characteristics of non-professional padel players, Courel-lbáñez and Herrera-Gálvez [13] showed that men padel players had good levels of cardiorespiratory fitness, upper body power, handgrip strength, speed and agility. However, players' tests of dynamic balance showed low values in both posterior and anterior directions. In another study, Courel et al. [19] showed that adult women that practised padel had higher levels of physical fitness than sedentary controls, due to their better body balance and explosive power, abdominal endurance, and cardiovascular capacity. Furthermore, they obtained lower waist and hip circumferences and thigh skinfold thicknesses compared to sedentary subjects.

In tennis, several sports-science and coaching staffs are regularly conducting test batteries combining general and specific tests for speed, agility, strength, power, endurance, musculoskeletal fitness, coordination and skill performance in both men and women players [18]. The optimal interpretation of these data is subsequently used in short- and long-term requirements to ensure the best possible preparation, but also to track players' progress, creating individual profiles and detecting injury risk $[18,20]$. Additionally, these investigations are gaining in interest given their general applicability, replicability and affordability [21]. Thus, the aims of the present study were (1) to examine the fitness characteristics of professional padel players and (2) to determine differences in physical performance regarding players' gender.

\section{Materials and Methods}

This analysis was conducted on data collected during a national players' meeting using a battery of standard anthropometric and physical performance tests.

\subsection{Participants}

Thirty professional padel players (men, $n=15$, women, $n=15$ ) agreed to take part in this study. Both the men and women players were classified in the top 50 of the World Padel Tour (WPT) ranking. A summary of participants' characteristics (anthropometric, training information, etc.) is presented in Table 1. All the participants were informed about the purpose of the study and signed a consent form before enrolling. The protocol was reviewed and approved by the Clinical Research Ethics Committee of the Department of Health and Consumption of the Government of Aragon (Spain) (21/2012). The sample was recruited by convenience, with a minimum sample size of 30 padel players (confidence level $=90 \%$; error range $=10 \%$ ).

\subsection{Procedure}

Testing protocols were conducted on four non-consecutive days with a minimum rest of $72 \mathrm{~h}$ between days. The tests were performed as follows: day one, isometric handgrip strength, sit and reach, $10 \times 5$ shuttle test; day two, countermovement jump, squat jump and Abalakov test; day three, one-repetition maximum test; day four, anthropometry and $\mathrm{VO}_{2}$ max test. To ensure standardisation of test administration, all tests were performed in the same order, using the same testing devices, measurement protocols and operators. The test sessions were performed in a laboratory. There was previous familiarisation with 
accurate testing procedures. A specific dynamic warm-up routine was carried out before the tests, consisting of joint movements, dynamic stretching, hopping exercises and jumps of increasing intensity. All the subjects were required to avoid ingesting caffeine or other types of stimulating substances, as well as intensive work sessions, from $48 \mathrm{~h}$ prior to the measurements.

Table 1. Characteristics of the professional women and men padel players.

\begin{tabular}{ccccccc}
\hline & $\begin{array}{c}\text { Women } \\
\text { M (SD) }\end{array}$ & SE & $\begin{array}{c}\text { Men } \\
\text { M (SD) }\end{array}$ & SE & df & $p$ \\
\hline Training per week (hours) & $24.1(3.3)$ & 0.86 & $23.5(3.7)$ & 1.02 & 0.452 & 0.655 \\
Experience & $10.8(3.5)$ & 0.88 & $8.1(3.1)$ & 0.79 & 2.298 & 0.029 \\
Age & $30.0(4.2)$ & 1.06 & $27.4(6.8)$ & 1.76 & 1.316 & 0.198 \\
Weight (kg) & $59.9(4.7)$ & 1.18 & $78.2(8.5)$ & 2.21 & -7.451 & $<0.001$ \\
Height (cm) & $166.6(4.8)$ & 1.2 & $177.9(4.0)$ & 1.02 & -7.108 & $<0.001$ \\
FM (\%) & $19.48(5.6)$ & 1.5 & $13.53(4.83)$ & 1.25 & 3.07 & 0.005 \\
\hline
\end{tabular}

FM: fat mass; M: mean; SD: standard deviation; SE: standard error of mean; $p$ : significant difference.

\subsection{Measurements}

Anthropometry. Anthropometric data were collected from all participants including height using a fixed stadiometer $( \pm 0.1 \mathrm{~cm}$; Seca 220, Seca, Hamburg, Germany), and weight using digital scales ( $\pm 0.1 \mathrm{~kg}$; Seca 714, Seca, Hamburg, Germany).

Fat mass. Anthropometric measurements were collected by the same experienced evaluator using specific equipment including a skinfold calliper (Holtain Ltd., Crymych, UK) accurate to the nearest $0.2 \mathrm{~mm}$. Eight skinfold thicknesses (biceps brachii, triceps, subscapular, iliac crest, supraspinal, abdominal, thigh, and medial calf), were measured. Body mass index (BMI) was calculated from the body mass $(\mathrm{kg})$ and height $\left(\mathrm{m}^{2}\right)$ relationship. Body fat percentage was calculated using the body density formula by Withers et al. (1987) [22], estimating the percentage of body fat with the Siri equation (1961) [23].

$\mathrm{VO}_{2}$ max. An incremental test was performed on a treadmill in the laboratory to determine $\mathrm{VO}_{2}$ max, (Pulsar HP, Cosmos, Nussdorf, Germany). After a warm-up of 3 min at $6 \mathrm{~km} \cdot \mathrm{h}^{-1}$, the test was carried out with a $1 \%$ incline, starting from a speed of $8 \mathrm{~km} \cdot \mathrm{h}^{-1}$ and with increments of $1 \mathrm{~km} \cdot \mathrm{h}^{-1}$ every minute until exhaustion. The collection of expired gases was carried out with an Oxycon Pro analyser (Jaegger, Germany).

One-Repetition Maximum Test. Maximal strength (1-RM) was determined according to the guidelines and recommendations described by (Brzycki, 1993) for untrained subjects on analysis of strength using 1-RM. It was determined indirectly by applying the equation for predicting 1-RM based on reps-to-fatigue [24] for the following tests: bench press, leg extension, leg curl, lat pulldowns, overhead press, and shoulder press. Two preliminary series were carried out, an initial one to control the technical execution of the movement and a warm-up series with an approximate load of from 30 to 50\% of the perceived 1-RM, the resistance being low enough to allow subjects to complete reps easily, separated by a one-minute rest interval. Two to three attempts were then made with $10-20 \%$ increments of the load, separated by rest intervals of 3-5 min. The 1-RM test ended when the players achieved a value less than or equal to five repetitions in each exercise. The same researcher evaluated 1-RM attempts in all exercises, ensuring that each athlete performed the full range of motion.

Countermovement Jump (CMJ). To provide information about the reactive strength of the lower limbs, a double leg vertical CMJ without arm swing (i.e., with the hands on the hips) was performed on a contact time platform (Newtest Powertimer 300-series, Newtest Oy, Tyrnävä, Finland) according to the established protocol [25]. During the test, an investigator confirmed the correct knee angle $\left(90^{\circ}\right)$. Each player performed two maximal attempts, interspersed with $45 \mathrm{~s}$ of passive recovery, and the maximum height (cm) determined by flight time was recorded.

Squat Jump (SJ). To provide information about leg power performance, an SJ from a stationary semi-squatting position $\left(90^{\circ}\right)$ was performed on a contact time platform 
(Newtest Powertimer 300-series, Newtest Oy, Tyrnävä, Finland) according to the established protocol [26]. Each player performed two maximal attempts interspersed with $45 \mathrm{~s}$ of passive recovery. The maximum height $(\mathrm{cm})$ determined by flight time was recorded.

Abalakov test (ABK). In the countermovement jump with arm swing (Newtest Powertimer 300-series, Newtest Oy, Tyrnävä, Finland), each player performed two maximal attempts interspersed with $45 \mathrm{~s}$ of passive recovery, and the maximum height $(\mathrm{cm})$ determined by flight time was recorded.

Isometric handgrip strength (HD). Handgrip strength was measured in the dominant and non-dominant hand. Players performed the test with the test arm fully extended in the vertical axis and not touching the body. A portable hand dynamometer Smedley III T-18A (Takei, Tokyo, Japan) was used for handgrip strength measurement. The hand dynamometer has a range between 0 and $100 \mathrm{~kg}$, with $0.5 \mathrm{~kg}$ increments and an accuracy of $\pm 2 \mathrm{~kg}$. Each subject made two attempts of maximal isometric contractions for $5 \mathrm{~s}$ with each hand. Rest time between each attempt was $2 \mathrm{~min}$. The dynamometer was adjusted to the participant' $s$ hand and the best of two maximal trials from each hand was used in data analysis.

Sit and Reach (SaR). The classic sit and reach test was performed to measure the flexibility of the lower back and hamstrings. The test involved sitting on the floor with legs stretched out straight ahead. The soles of the feet were placed flat against the box. Both knees were locked and pressed flat to the floor-the tester assisted by holding them down. With the palms facing downwards, and the hands-on top of each other or side by side, the subject reached forward along the measuring line as far as possible, holding that position for one to two seconds while the distance was recorded in $\mathrm{cm}$.

$10 \times 5 \mathrm{~m}$ Shuttle Test. This test was performed to measure agility (accelerations and decelerations) with change in direction. Time was recorded using a photocell gate (Newtest Powertimer 300-series, Newtest Oy, Tyrnävä, Finland) and software (Newtest PowertimerPC software 2.0 for windows), with an accuracy of $\pm 0.001 \mathrm{~s}$. Timing was activated and stopped when the player passed through the gate.

\subsection{Statistical Analysis}

Exploratory data analysis included mean and standard deviation descriptive statistics, searching for outliers and assessing the normality of distribution by means of the ShapiroWilk test. Levene's test was used to confirm the equality of variances. Student's $t$-test was used to determine the possible differences in each variable according to players' gender. Effect sizes (d) were estimated by calculating the $95 \%$ confidence intervals for Cohen's d and interpreted as follows [26]: Trivial $(<0.21)$, Small $(0.2$ to $<0.60)$, Moderate $(0.60$ to $<1.2)$, Large $(1.2$ to $<2.0)$, Very Large $(2.0$ to $<4.0)$, and Extremely Large $(\geq 4.0)$. The significance level was set at $p<0.05$. Data analyses were performed using the SPSS statistical software package (version 25.0; SPSS, Inc., Chicago, IL, USA).

\section{Results}

The results of the test performance are presented in Table 2 . The men players recorded higher values in $\mathrm{VO}_{2}$ max than the women $(p<0.001)$. In all the one maximum repetition tests, the men players showed significantly higher values than the women $(p<0.001$; ES: from 1.36 to 3.73 ), except in the 1-RM S test ( $p=0.205$; ES: 0.74) (Figure 1). Moreover, men players jumped higher in all tests (CMJ, SJ, and ABK), although just CMJ and ABK showed significant differences ( $p=0.002$; ES: 1.19 and $p=0.01$; ES: 1.22 , respectively) (Figure 1). No significant differences were found in the SaR test $(p>0.05)$, although men players obtained significantly lower scores in the agility test than women players $(p=0.002$; ES: 1.21). Finally, Mean and individual values in the four largest measurements concerning gender differences are shown in Figure 2 
Table 2. Differences in physical test by gender.

\begin{tabular}{|c|c|c|c|c|c|c|}
\hline Variables/Test & $\begin{array}{l}\text { Women } \\
\text { M (SD) }\end{array}$ & SE & $\begin{array}{c}\text { Men } \\
\text { M (SD) }\end{array}$ & SE & df & $p$ \\
\hline \multicolumn{7}{|l|}{ Physical } \\
\hline HRmax (lat. $\left.\min ^{-1}\right)$ & $187.53(9.83)$ & 2.53 & 185.35 (10.47) & 2.80 & 0.577 & 0.569 \\
\hline $\mathrm{VO}_{2} \max (\mathrm{mL} / \mathrm{kg} / \mathrm{min})$ & $46.77(4.57)$ & 1.22 & $55.43(7.04)$ & 1.82 & -3.895 & $<0.001$ \\
\hline \multicolumn{7}{|l|}{ Repetition maximum (1-RM) } \\
\hline $1-\mathrm{RM} \mathrm{BP}$ & $38.89(9.87)$ & 2.54 & $66.40(24.92)$ & 6.66 & -4.075 & $<0.001$ \\
\hline 1-RM LP & $88.78(16.3)$ & 4.52 & $143.22(31.94)$ & 10.1 & -5.333 & $<0.001$ \\
\hline 1-RM LE & $84.41(20.37)$ & 5.26 & $142.35(36.62)$ & 9.46 & -5.354 & $<0.001$ \\
\hline 1-RM S & $135.37(31.1)$ & 8.31 & $179.23(73.87)$ & 19.07 & -2.056 & 0.205 \\
\hline 1-RM LC & $72.82(20.65)$ & 5.33 & $131.78(56.11)$ & 14.49 & -3.819 & $<0.001$ \\
\hline 1-RM LaP & $45.45(5.43)$ & 1.4 & $89.09(15.4)$ & 4.12 & -10.323 & $<0.001$ \\
\hline 1-RM OP & $23.57(7.7)$ & 2.06 & $60.82(13.78)$ & 3.68 & -8.828 & $<0.001$ \\
\hline 1-RM SP & $36.94(9.19)$ & 2.37 & $105.21(52.12)$ & 14.46 & -4.999 & $<0.001$ \\
\hline \multicolumn{7}{|l|}{ Explosive jumps } \\
\hline $\mathrm{CMJ}(\mathrm{cm})$ & $24.33(5.4)$ & 1.39 & $32.67(7.98)$ & 2.06 & -3.349 & 0.002 \\
\hline $\mathrm{SJ}(\mathrm{cm})$ & $21.55(4.65)$ & 1.2 & $26.67(8.77)$ & 2.26 & -1.998 & 0.135 \\
\hline $\mathrm{ABK}(\mathrm{cm})$ & $29.29(5.35)$ & 1.38 & $39.07(9.68)$ & 2.5 & -3.425 & 0.010 \\
\hline \multicolumn{7}{|l|}{ Dynamometry } \\
\hline HD D (kg) & $33.72(5.64)$ & 1.41 & $51.14(9.19)$ & 2.37 & -6.41 & $<0.001$ \\
\hline HD ND (kg) & $27.41(3.33)$ & 0.83 & $46.19(8.06)$ & 2.08 & -8.581 & $<0.001$ \\
\hline \multicolumn{7}{|l|}{ Flexibility and agility } \\
\hline $\mathrm{SaR}(\mathrm{cm})$ & 34.32 (7.59) & 2.03 & $28.27(10.39)$ & 2.68 & 1.779 & 0.087 \\
\hline $10 \times 5(\mathrm{~s})$ & $17.62(1.15)$ & 0.31 & $16.16(1.2)$ & 0.31 & 3.345 & 0.002 \\
\hline
\end{tabular}

M: mean; SD: standard deviation; SE: standard error of mean; $p$ : significant difference; 1-RM: one repetition maximum; BP: bench press; LP: leg press; LE: leg extension; LC: leg curl; LaP: lat pulldowns; OP: overhead press; SP: shoulder press; CMJ: countermovement jump; ABK: Abalakov; HD: hand dynamometer; D: dominant; ND: non-dominant; SaR: sit and reach.

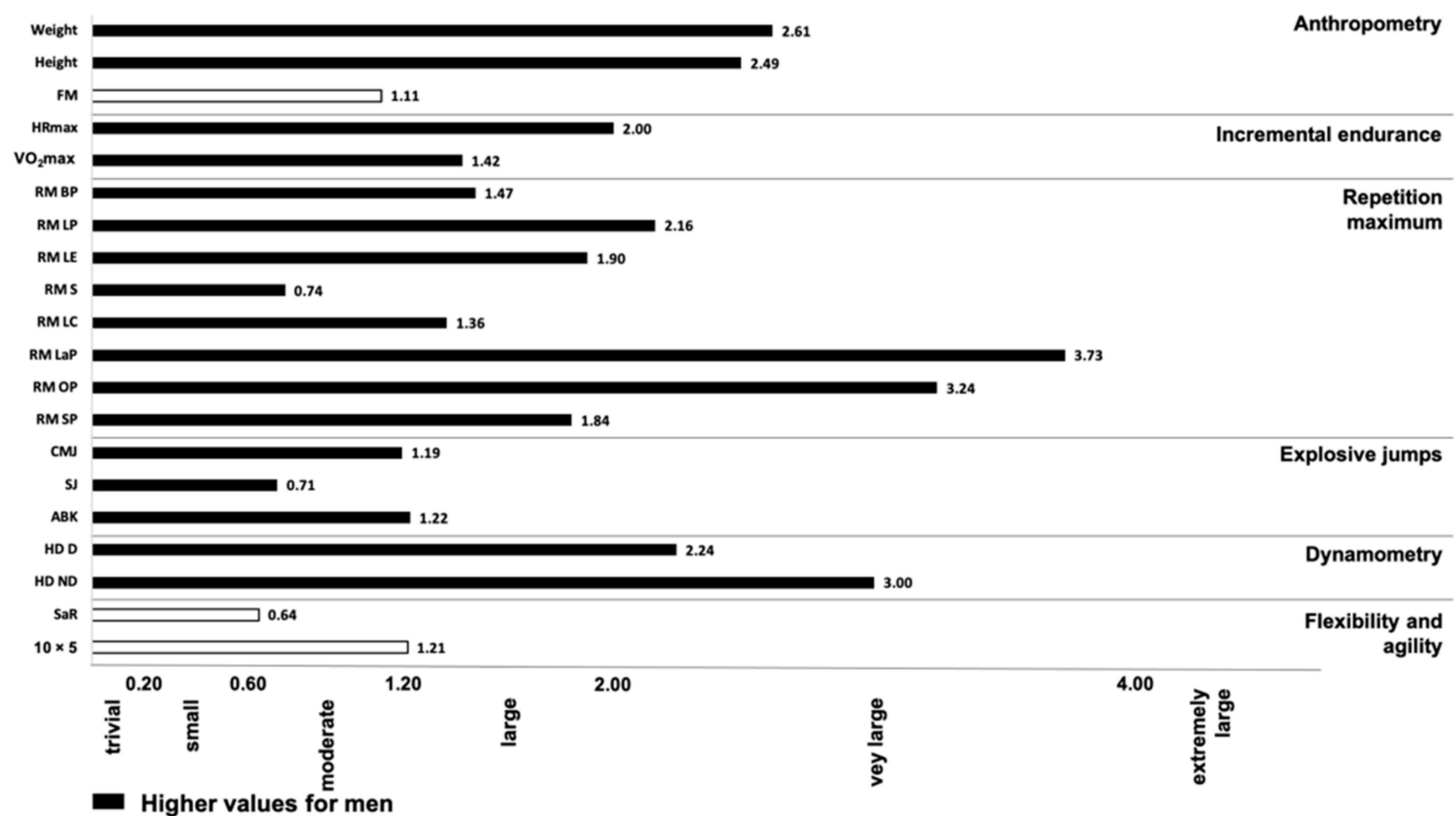

Effect size

Figure 1. Effect sizes for the gender differences in physical parameters of professional padel players. FM: fat mass; RM: one repetition maximum; BP: bench press; LP: leg press; LE: leg extension; LC: leg curl; LaP: lat pulldowns; OP: overhead press; SP: shoulder press; CMJ: countermovement jump; ABK: Abalakov; HD: hand dynamometer; D: dominant; ND: non-dominant; SaR: sit and reach. 

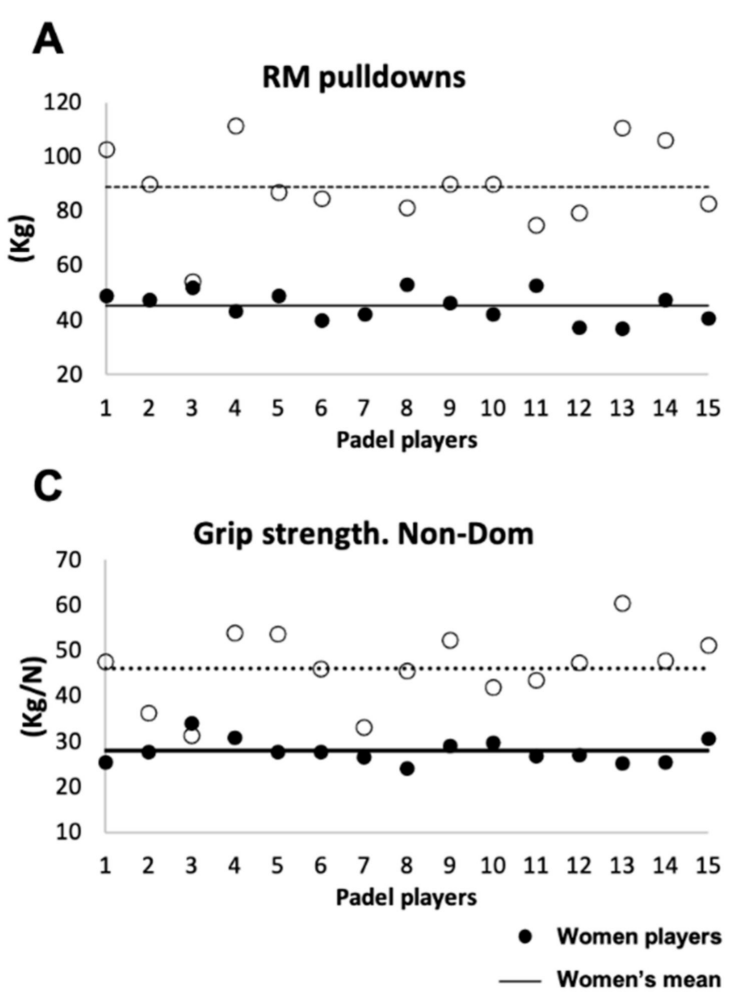

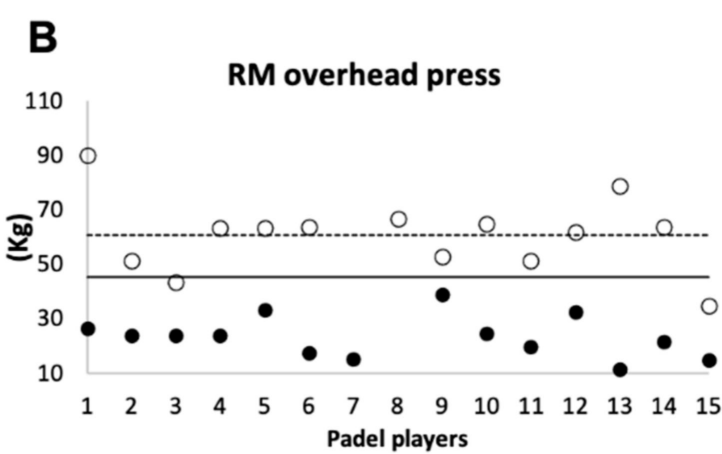

D

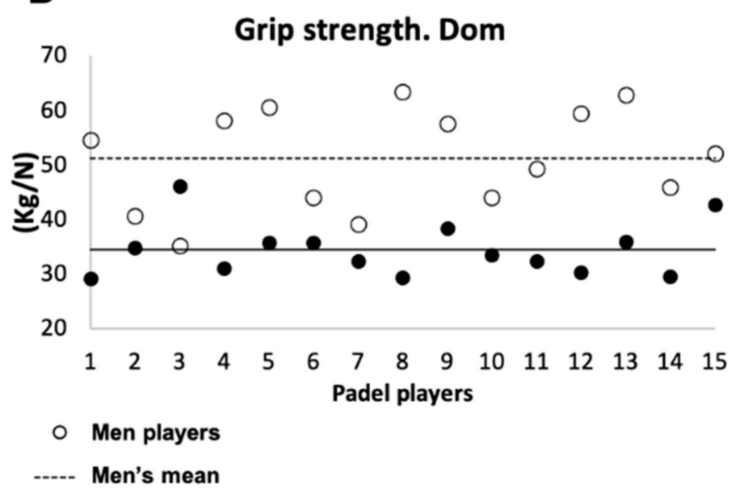

Figure 2. Mean and individual values in the four largest measurements concerning gender differences. RM: one repetition maximum. Non-Dom: non-dominant; Dom: dominant. Kg: kilogram. (A) one repetition maximum pulldowns; (B) one repetition maximum overhead press; (C) grip strength Non-dominant arm; (D) grip strength dominant arm.

\section{Discussion}

The main objective of this study was to examine the fitness characteristics of professional padel players and to determine differences in physical performance regarding players' gender. This is the first study to evaluate physical fitness (e.g., $\mathrm{VO}_{2}$ max, maximal dynamic strength, hand grip or explosive jumps) in professional men and women padel players. Such knowledge is essential to identify determinant factors in game performance, competitive success and injury prevention in padel.

A few studies have examined physical characteristics related to padel players $[11,12,27]$. Our results showed that men players had higher values in terms of weight, height and $\mathrm{VO}_{2}$ max than women players, and lower values of fat mass percentage. Fat mass results are similar to those obtained in other racket sport studies [12,27-29], where the range obtained was between $15-19 \%$ in women players and $12-15 \%$ in men. It seems that the energy requirements of padel are closer to those reported previously for tennis [30]. Currently, Campa et al. [31] developed a cross-sectional observational study on 1556 athletes, sorted into three groups: endurance, velocity-power, and team sports, obtaining similar results to ours for the velocity-power group, which included tennis.

The $\mathrm{VO}_{2}$ max results are similar to those of other racket sports, such as tennis [29,30,32], indicating that padel provokes very similar physiological demands and adaptions. The same results were obtained by Carrasco et al. (2011) when evaluating twelve top-level padel players [33]. However, several studies observed higher values of $\mathrm{VO}_{2}$ max in squash players, where game intensity is higher than in padel [34,35].

The modern game of padel has become a sport where strength and explosive actions in upper and lower limbs have gained great relevance for success, for example, in shortdistance sprints and changes in direction $[13,14,36]$. In this regard, the smash stroke is the game action producing the highest percentage of winners in padel [7,33], and greatly influences the match outcome. A recent study reported that men players can finish the point with a smash from $7 \mathrm{~m}$ to the net [37], while women perform it closer to the net. 
These authors attribute these results to anthropometric and strength differences, which reflects the importance of strength in this sport. Due to the lower strength and power levels of women players compared with men, we can suggest that performance in women players could be more related to aerobic fitness. In addition, a longer playing time and total time has been observed in women over men players, as well as in the number and type of stroke [6], using more trays and less flat and topspin smashes (powerful strokes) than men [37].

In addition, power, is probably the most important factor in determining success in many sports [18]. In men's padel players, the obtained results are lower than those found in other racket sports [38]. It is likely that, in tennis, strength may be more determinant, and used in actions more frequently than in padel. Therefore, the power developed in serve and baseline strokes in a tennis match is greater than in padel, where the smash is the most explosive action related to success.

Significant differences have been observed between genders in almost all fitness parameters, especially in the upper limbs, in both maximal dynamic and explosive strength. Previous research showed that men perform more explosive shots and jumps and overhead strokes, such as powerful smashes, while women's game pace (shots/sec ratio) is slower $[37,39]$. In light of these findings, coaches and players should consider incorporating upper limb strengthening exercises in their training routine. Regarding explosive jumps, men and women padel players showed a similar CMJ performance to tennis players [18,20], but lower than those of badminton players [40], with higher values in the men in CMJ (32.67 vs. 24.33) and $A B K$ (39.70 vs. 29.29). Unlike tennis and badminton, the padel groundstroke appears to be a low-power demanding action, in which accuracy and anticipation skills prevail [40].

On the other hand, hand-grip dynamometry showed higher values in padel players than in under-18 tennis players [18], probably due to the predominance of short, fast strokes in padel. Grip strength has been demonstrated to be a good indicator of service speed in junior tennis players [41]. This parameter could be very interesting to evaluate in padel players, where a lot of actions require high values of grip strength, such as smashes or volleys. Finally, padel is an intermittent sport, including continuous changes in direction, where agility could be an important factor related to performance. The game demands fast reactions, leg and whole-body movements and an ability to change direction quickly. The results obtained in the $10 \times 5$-metre shuttle run are similar to those of other racket sports, such as squash [42], indicating than padel could have a high demand for these movements, directly related to performance.

This study was strengthened by the novelty and the relevance of the sample (worldclass padel players) and the multifaceted performance evaluation. Furthermore, the use of field tests has been shown to enhance replicability and applicability to the conditioning training sessions. Nonetheless, there are several limitations that must be acknowledged. It is worth noting that we used traditional methods to evaluate 1RM of the different exercises. Alternatively, the 1RM could be accurately estimated by measuring the barbell/machine velocity (i.e., velocity-based approach), thus avoiding the risk of injury and fatigue status related to $1 \mathrm{RM}$ tests $[43,44]$. Additionally, shoulder internal/external rotation strength tests or shoulder ROM were not used. There are different studies in racket sports that show a relationship with hitting speed as well as risk of injury due to imbalances [45,46]. Moreover, field tests such as medicine ball throws or smash velocity were not included, and players' hand-dominance was not considered.

\section{Conclusions}

Padel is a high-intensity intermittent sport, where players perform short, high-intensity sprints, with changes in direction, hitting high balls and jumping to make different strokes throughout the game. This is the first study to analyse the physical fitness characteristics in professional padel players. The results of this study show that padel players presented anthropometric and physical differences according to gender. They show higher explosive 
strength values in men players than in women players, in line with the demands of the competition, with shorter point lengths and more explosive strokes (smashes) in the men than the women. As one of the most important principles in training is individualisation, physical trainers now have cardiorespiratory, strength and agility values that can be considered for optimising training and testing procedures for professional padel players.

Author Contributions: Conceptualization, F.P. and A.S.-P.; methodology, F.P., A.S.-P., D.M. and B.J.S.-A.; software, F.P., A.S.-P. and D.M.; validation, F.P., A.S.-P., D.M. and B.J.S.-A.; formal analysis, F.P., A.S.-P., D.M. and B.J.S.-A.; investigation, F.P.; resources, F.P., A.S.-P., D.M. and B.J.S.-A.; data curation, A.S.-P.; writing-original draft preparation, A.S.-P., D.M. and B.J.S.-A.; writing-review and editing, F.P., A.S.-P., D.M. and B.J.S.-A.; visualization, F.P., A.S.-P., D.M. and B.J.S.-A.; supervision, F.P., A.S.-P., D.M. and B.J.S.-A.; project administration, F.P.; funding acquisition, F.P. All authors have read and agreed to the published version of the manuscript.

Funding: This research was subsidised through a research grant received by the Institute of $\mathrm{Al}$ toaragoneses Studies of the Provincial Council of Huesca (Spain) and through public funds received from the General Directorate of Research and Innovation of the Government of Aragon to the research group Training, Physical Activity and Sports Performance (ENFYRED).

Institutional Review Board Statement: The study was conducted according to the guidelines of the Declaration of Helsinki and approved by the Clinical Research Ethics Committee of the Department of Health and Consumption of the Government of Aragon (Spain) (21/2012).

Informed Consent Statement: Informed consent was obtained from all subjects involved in the study.

Data Availability Statement: The data presented in this study are available on request from the corresponding author.

Acknowledgments: Special thanks to the entire medical team of the Sports Medicine Centre of the Government of Aragon, especially to the Director, Juan José Lacleta. Thanks to each and every one of the players participating in this study.

Conflicts of Interest: The authors declare no conflict of interest.

\section{References}

1. International Padel Federation. Rules of Padel; FIP: Lausanne, Switzerland, 2020.

2. Courel-Ibáñez, J.; Sánchez-Alcaraz, B.J.; García, S.; Echegaray, M. Evolution of padel in Spain according to practitioners' gender and age [Evolución del pádel en España en función del género y edad de los practicantes]. Cult. Cienc. Deport. 2017, $12,39-46$. [CrossRef]

3. Courel-Ibáñez, J.; Sánchez-Alcaraz, B.J.; Muñoz, D. Exploring game dynamics in padel: Implications for assessment and training. J. Strength Cond. Res. 2019, 33, 1971-1977. [CrossRef]

4. Courel-Ibáñez, J.; Sánchez-Alcaraz, B.J.; Cañas, J. Game performance and length of rally in professional padel players. J. Hum. Kinet. 2017, 55, 161-169. [CrossRef] [PubMed]

5. Sañudo, B.; De Hoyo, M.; Carrasco, L. Structural characteristics and physiological demands of the paddle competition [Demandas fisiológicas y características estructurales de la competición en pádel masculino]. Apunt. Educ. Física Deportes 2008, 94, 23-28.

6. Torres-Luque, G.; Ramirez, A.; Cabello-Manrique, D.; Nikolaidis, P.T.; Alvero-Cruz, J.R. Match analysis of elite players during paddle tennis competition. Int. J. Perform. Anal. Sport 2015, 15, 1135-1144. [CrossRef]

7. Priego, J.I.; Olaso, J.; Llana, S.; Pérez, P.; Gonález, J.C.; Sanchís, M. Padel: A quantitative study of the shots and movements in the high-performance. J. Hum. Sport Exerc. 2013, 8, 925-931. [CrossRef]

8. Ramón-Llin, J.; Guzmán, J.; Llana, S.; Vuckovic, G.; Muñoz, D.; Sánchez-Alcaraz, B.J. Analysis of distance covered in padel based on level of play and number of points per match [Análisis de la distancia recorrida en pádel en función del nivel de juego y el número de puntos por partido]. Retos Nuevas Tend. Educ. Fis. Deport Recreacion 2020, 39, 205-209.

9. Courel-Ibáñez, J.; Sánchez-Alcaraz, B.J.; Cañas, J. Effectiveness at the net as a predictor of final match outcome in professional padel players. Int. J. Perform. Anal. Sport 2015, 15, 632-640. [CrossRef]

10. Sánchez-Alcaraz, B.J.; Muñoz, D.; Pradas, F.; Ramón-Llin, J.; Cañas, J.; Sánchez-Pay, A. Analysis of serve and serve-return strategies in elite male and female padel. Appl. Sci. 2020, 10, 6693. [CrossRef]

11. Castillo-Rodríguez, A.; Alvero-Cruz, J.R.; Hernández-Mendo, A.; Fernández-García, J.C. Physical and physiological responses in paddle tennis competition. Int. J. Perform. Anal. Sport 2014, 14, 524-534. [CrossRef]

12. Pradas, F.; Cachón, J.; Otín, D.; Quintas, A.; Arraco, S.I.; Castellar, C. Anthropometric, physiological and temporal analysis in elite female paddle players [Análisis antropométrico, fisiológico y temporal en jugadoras de pádel de elite]. Retos Nuevas Tend. Educ. Fís. Deport Recreación 2014, 25, 107-122. 
13. Courel-Ibáñez, J.; Herrera-Gálvez, J. Fitness testing in padel: Performance differences according to players' competitive level. Sci. Sports 2020, 35, 11-19. [CrossRef]

14. Castillo, R.; Casuso, M. Incidence of musculoskeletal sport injuries in a sample of male and female recreational paddle-tennis players. J. Sports Med. Phys. Fit. 2017, 57, 816-821.

15. Kraemer, W.J.; Häkkinen, K.; Triplett-McBride, N.T.; Fry, A.C.; Koziris, L.P.; Ratamess, N.A.; Bauer, J.E.; Volek, J.S.; McConnell, T.; Newton, R.U.; et al. Physiological changes with periodized resistance training in women tennis players. Med. Sci. Sports Exerc. 2003, 35, 157-168. [CrossRef] [PubMed]

16. Ramón-Llin, J.; Guzmán, J.F.; Llana, S.; James, N.; Vučković, G. Analysis of padel rally caracteristics for three competitive levels. Kinesiol. Slov. 2017, 23, 39-49.

17. Baiget, E.; Fernández-Fernández, J.; Iglesias, X.; Vallejo, L.; Rodríguez, F.A. On-court endurance and performance testing in competitive male tennis players. J. Strength Cond. Res. 2014, 28, 256-264. [CrossRef]

18. Fernandez-Fernandez, J.; Ulbricht, A.; Ferrauti, A. Fitness testing of tennis players: How valuable is it? Br. J. Sports Med. 2014, 48, i22-i31. [CrossRef] [PubMed]

19. Courel-Ibáñez, J.; Cordero, J.C.; Muñoz, D.; Sánchez-Alcaraz, B.J.; Grijota, F.J.; Robles, M.C. Fitness benefits of padel practice in middle-aged adult women. Sci. Sports 2018, 33, 291-298. [CrossRef]

20. Ulbricht, A.; Fernandez-Fernandez, J.; Mendez-Villanueva, A.; Ferrauti, A. Impact of fitness characteristics on tennis performance in elite junior tennis players. J. Strength Cond. Res. 2016, 30, 989-998. [CrossRef]

21. Pyne, D.B.; Spencer, M.; Mujika, I. Improving the value of fitness testing for football. Int. J. Sports Physiol. Perform. 2014, 9 , 511-514. [CrossRef]

22. Withers, R.T.; Craig, N.P.; Bourdon, P.C.; Norton, K.I. Relative body fat and anthropometric prediction of body density of male athletes. Eur. J. Appl. Physiol. Occup. Physiol. 1987, 56, 191-200. [CrossRef] [PubMed]

23. Siri, W. Body composition from fluid spaces and density: Analysis of methods. In Techniques for Measuring Body Composition; Brozek, J., Henschel, A., Eds.; National Academy of Sciences: Washington, DC, USA, 1961; pp. 223-244.

24. Brzycki, M. Strength testing-Predicting a one-rep max from reps-to-fatigue. J. Phys. Educ. Recreat. Danc. 1993, 64, 88-90. [CrossRef]

25. Hughes, S.; Warmenhoven, J.; Haff, G.G.; Chapman, D.W.; Nimphius, S. Countermovement jump and squat jump force-time curve analysis in control and fatigue conditions. J. Strength Cond. Res. 2021. [CrossRef]

26. Hopkins, W.G.; Marshall, S.W.; Batterham, A.M.; Hanin, J. Progressive statistics for studies in sports medicine and exercise science. Med. Sci. Sports Exerc. 2009, 41, 3-12. [CrossRef]

27. Pradas, F.; González-Jurado, J.A.; García-Giménez, A.; Gallego, F.; Castellar, C. Anthropometric characteristics of elite paddle players. Pilot Study 2019, 19, 181-195.

28. Sanchis, J.; Dorado, C.; Calbet, J. Regional body composition in profesional tennis players. In Science and Racket Sports II; Less, A., Maynard, I., Hughes, M., Reilly, T., Eds.; E \&FN Spon: London, UK, 1998; pp. 34-40.

29. Bergeron, M.F.; Maresh, C.M.; Kraemer, W.J.; Abraham, A.; Conroy, B.; Gabaree, C. Tennis: A physiological profile during match play. Int. J. Sports Med. 1991, 12, 474-479. [CrossRef]

30. Ferrauti, A.; Bergeron, M.F.; Pluim, B.M.; Weber, K. Physiological responses in tennis and running with similar oxygen uptake. Eur. J. Appl. Physiol. 2001, 85, 27-33. [CrossRef]

31. Campa, F.; Silva, A.M.; Matias, C.N.; Monteiro, C.P.; Paoli, A.; Nunes, J.P.; Talluri, J.; Lukaski, H.; Toselli, S. Body water content and morphological characteristics modify bioimpedance vector patterns in volleyball, soccer, and rugby players. Int. J. Environ. Res. Public Health 2020, 17, 6604. [CrossRef]

32. Baiget, E.; Fernández-Fernández, J.; Iglesias, X.; Rodríguez, F.A. Tennis play intensity distribution and relation with aerobic fitness in competitive players. PLoS ONE 2015, 10, e0131304. [CrossRef]

33. Carrasco, L.; Romero, S.; Sañudo, B.; de Hoyo, M. Game analysis and energy requirements of paddle tennis competition. Sci. Sport 2011, 26, 338-344. [CrossRef]

34. Jones, T.W.; Williams, B.K.; Kilgallen, C.; Horobeanu, C.; Shillabeer, B.C.; Murray, A.; Cardinale, M. A review of the performance requirements of squash. Int. J. Sports Sci. Coach. 2018, 13, 1223-1232. [CrossRef]

35. Girard, O.; Sciberras, P.; Habrard, M.; Hot, P.; Chevalier, R.; Millet, G.P. Specific incremental test in elite squash players. Br. J. Sports Med. 2005, 39, 921-926. [CrossRef]

36. Sánchez-Alcaraz, B.J.; Courel-Ibáñez, J.; Cañas, J. Groundstroke accuracy assesment in padel players according to their level of play [Valoración de la precisión de golpeo en jugadores de pádel en función de su nivel de juego]. RICYDE Rev. Int. Cienc. Deporte 2016, 12, 323-333.

37. Sánchez-Alcaraz, B.J.; Perez-Puche, D.T.; Pradas, F.; Ramón-Llín, J.; Sánchez-Pay, A.; Muñoz, D. Analysis of performance parameters of the smash in male and female professional padel. Int. J. Environ. Res. Public Health 2020, 17, 7027. [CrossRef]

38. Desgorces, F.D.; Berthelot, G.; Dietrich, G.; Testa, M.S.A. Local muscular endurance and prediction of 1 repetition maximum for bench in 4 athletic populations. J. Strength Cond. Res. 2010, 24, 394-400. [CrossRef]

39. Escudero-Tena, A.; Fernández-Cortes, J.; García-Rubio, J.; Ibáñez, S.J. Use and efficacy of the lob to achieve the offensive position in women's professional padel. Analysis of the 2018 WPT finals. Int. J. Environ. Res. Public Health 2020, 17, 4061. [CrossRef] [PubMed] 
40. Fuchs, M.; Faude, O.; Wegmann, M.; Meyer, T. Critical evaluation of a badminton-specific endurance test. Int. J. Sports Physiol. Perform. 2014, 9, 249-255. [CrossRef]

41. Fett, J.; Ulbricht, A.; Ferrauti, A. Impact of physical performance and anthropometric characteristics on serve velocity in elite junior tennis players. J. Strength Cond. Res. 2020, 34, 192-202. [CrossRef]

42. Todd, M.; Mahoney, C. Determination of pre-season physiological characteristics of elite male squash players. In Sience and Racket Sports I; Reilly, T., Hughes, M., Lees, A., Eds.; Spon Press: London, UK, 1995; pp. 81-88.

43. Martínez-Cava, A.; Morán-Navarro, R.; Hernández-Belmonte, A.; Courel-Ibáñez, J.; Conesa-Ros, E.; González-Badillo, J.J.; Pallarés, J.G. Range of motion and sticking region effects on the bench press load-velocity relationship. J. Sports Sci. Med. 2019, 18, 645-652.

44. Hernández-Belmonte, A.; Martínez-Cava, A.; Morán-Navarro, R.; Courel-Ibáñez, J.; Pallarés, J. A comprehensive analysis of the velocity-based method in the shoulder press exercise: Stability of the load-velocity relationship and sticking region parameters. Biol. Sport 2021, 38, 235-243. [CrossRef]

45. Hayes, M.J.; Spits, D.R.; Watts, D.G.; Kelly, V.G. Relationship between tennis serve velocity and select performance measures. J. Strength Cond. Res. 2021, 35, 190-197. [CrossRef] [PubMed]

46. Fernandez-Fernandez, J.; Nakamura, F.Y.; Moreno-Perez, V.; Lopez-Valenciano, A.; Del Coso, J.; Gallo-Salazar, C.; Barbado, D.; Ruiz-Perez, I.; Sanz-Rivas, D. Age and sex-related upper body performance differences in competitive young tennis players. PLoS ONE 2019, 14, e0221761. [CrossRef] [PubMed] 